\title{
Investigating the intentions of tourism providers and trade exhibition visitors to use technology: A technology acceptance model approach
}

\begin{tabular}{|c|c|}
\hline \multicolumn{2}{|c|}{$\begin{array}{l}\text { Authors: } \\
\text { Magdalena P. (Nellie) Swart }{ }^{1} \\
\text { Marios D. Sotiriadis } 1 \\
\text { Willy H. Engelbrecht }^{2} \text { (D) }\end{array}$} \\
\hline \multicolumn{2}{|c|}{$\begin{array}{l}\text { Affiliations: } \\
{ }^{1} \text { Department of Applied } \\
\text { Management, University of } \\
\text { South Africa, Pretoria, } \\
\text { South Africa }\end{array}$} \\
\hline \multicolumn{2}{|c|}{$\begin{array}{l}{ }^{2} \text { Faculty of Commerce, } \\
\text { The Independent Institute } \\
\text { of Education (Pty) Ltd, } \\
\text { Johannesburg, South Africa }\end{array}$} \\
\hline \multicolumn{2}{|c|}{$\begin{array}{l}\text { Corresponding author: } \\
\text { Marios Sotiriadis, } \\
\text { sotermarios@gmail.com }\end{array}$} \\
\hline \multicolumn{2}{|c|}{$\begin{array}{l}\text { Dates: } \\
\text { Received: } 19 \text { July } 2018 \\
\text { Accepted: } 15 \text { Jan. } 2019 \\
\text { Published: } 18 \text { June } 2019\end{array}$} \\
\hline \multicolumn{2}{|c|}{$\begin{array}{l}\text { How to cite this article: } \\
\text { Swart, M.P., Sotiriadis, M.D. } \\
\text { \& Engelbrecht, W.H., 2019, } \\
\text { 'Investigating the intentions } \\
\text { of tourism providers and } \\
\text { trade exhibition visitors to } \\
\text { use technology: A technology } \\
\text { acceptance model approach', } \\
\text { Acta Commercii 19(1), a693. } \\
\text { https://doi.org/10.4102/ } \\
\text { ac.v19i1.693 }\end{array}$} \\
\hline \multicolumn{2}{|c|}{$\begin{array}{l}\text { Copyright: } \\
\text { (C) 2019. The Authors } \\
\text { Licensee: AOSIS. This } \\
\text { is licensed under the } \\
\text { Creative Commons } \\
\text { Attribution License. }\end{array}$} \\
\hline \multicolumn{2}{|l|}{ Read online: } \\
\hline 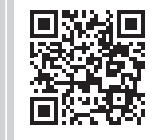 & $\begin{array}{l}\text { Scan this QR } \\
\text { code with your } \\
\text { smart phone or } \\
\text { mobile device } \\
\text { to read online. }\end{array}$ \\
\hline
\end{tabular}

Orientation: This article considered the use of technological tools by tourism trade exhibition visitors from a marketing perspective.

Research purpose: The main aim of this article was to investigate the adoption and use of technology by tourism providers within the context of business events and exhibitions.

Motivation for the study: To inform the tourism business practitioners about the efficient and appropriate uses of technological platforms in connecting and interacting with potential stakeholders at tourism events or exhibitions.

Research design, approach and method: A conceptual model was suggested and four hypotheses were advanced and empirically tested for the prediction of a business tourist's intention to accept technology (BTIAT) model. The target population was professional exhibition visitors - consisting of six groups: hunters, sport shooters, gun collectors, game farmers, professional hunters and anglers - who attended HuntEx 2015 (sample size = 403). A quantitative, inductive research approach was adapted, while general linear modelling (GLM) was applied to analyse the data.

Main findings: The study's findings indicate that business tourists' intention to use online technology was explained when the interaction between business tourists' perceived usefulness of online technology and business tourists' perceived ease of use of online technology are entered into the equation.

Practical/managerial implications: The providers of business tourism services (owners and managers) should consider the development of mobile applications to enhance the overall experience of business tourists when attending an event or exhibition, on condition that the application is relevant to the event and easy to use.

Contribution/value-add: The study suggested the adequate adoption and efficient uses of mobile applications by business tourism providers as a tool in improving and rendering more attractive the tourists' experience.

Keywords: technology acceptance; intention to use; ease of use; technology usefulness; business event tourism; exhibition.

\section{Introduction}

Tourism and travel-related industries are one of the world's largest economic sectors. In total, travel and tourism industries generated US $\$ 7.6$ trillion $(10.2 \%$ of global gross domestic product [GDP]) and 292 million work positions in 2016, equivalent to one in 10 jobs in the global economy (WTTC 2017). The World Travel \& Tourism Council (2017) indicated that the growth of the tourism industry would be steady and expected a growth rate of $3.6 \%$ for the year 2018 . The growth and expansion of technology and the usage thereof among tourists are adding to the tourism industry, which is becoming more technology friendly and using it as a means of increasing revenue and opportunities (Kennedy-Eden \& Gretzel 2012).

With the increase in the availability of mobile applications, such as Picksie and TouristEye, the providers of tourism services could use mobile applications as a form of interacting and connecting with consumers even if the mobile application is not tourism specific (De Oliveira Nunes \& Mayer 2014; Dinh et al. 2011; Kennedy-Eden \& Gretzel 2012). According to De Oliveira Nunes and Mayer (2014), the use of a mobile application within the tourism industry could enhance the tourist experience as well as increase the level of activity and interaction between tourists and service providers. Mobile applications could be used by tourism providers in ensuring that consumers are continuously updated and informed (Gavalas et al. 2012; Xia, Zhang \& Zhang 2018) about the 
services and products available, as well as to communicate with consumers to promote services and special offers.

The challenge for tourism providers is to comprehend in which ways technology could be used to influence tourist decision-making and behaviour, to adopt appropriate approaches and implement suitable strategies within the digital environment (Kennedy-Eden \& Gretzel 2012).

Furthermore, the review of literature indicated that this topic has not been sufficiently researched and explored by academic research. Academic scholars such as Sigala, Gretzel and Christou (2012) and Wang et al. (2016) indicated that future research should focus on better understanding the ways in which the Internet and Web 2.0 affect travel planning behaviour.

Ayeh (2015) and Huang et al. (2013) pointed out that some studies were performed in the following contexts of tourism and hospitality industries:

- Hospitality industry: the employees' acceptance of information technology in upmarket hotels (Lam, Cho \& Qu 2007), the front-office systems in hotels (Kim, Lee \& Law 2008b), various information systems (Huh, Kim \& Law 2009), restaurant computing systems (Ham, Kim \& Forsythe 2008), adoption of biometric systems in hotels (Morosan 2010) and self-service hotel technology adoption by tourists (Kaushik, Agrawal \& Rahman 2015; Xia et al. 2018)

- Other tourism settings: reservation systems used by travel agencies (Lee, Kim \& Lee 2006), and mobile social tourism shopping (Hew et al. 2018).

It is believed that very little research has been conducted within the tourism and hospitality contexts and settings regarding technology acceptance models (see, for instance, Kim et al. 2008b) and not all research within the context of an emerging demand and supply market, an inbound and outbound tourism destination, such as South Africa. There is limited empirical investigation of the adoption of the technology acceptance model (TAM) within a South African context, specifically in the context of business event tourism.

Business events include meetings, conventions, conferences, trade shows, exhibitions and incentive travel. Exhibitions are events in which products, services or promotional materials are displayed to attendees visiting exhibits on the show floor. These events focus primarily on the business-to-business (B2B) relationships and therefore are mostly closed to the public. However, to build the relationship between business and consumers, certain days of an exhibition are opened for the public to attend (Morrison 2019).

A business provider travels for work-related purposes, for example to attend a conference, trade show or exhibition (Swart \& Roodt 2009). Recently, Swart and Engelbrecht (2017) investigated the moderating effect of market segmentation among factors determining expo technology acceptance in the context of exhibitions, suggesting that the predictive nature of these variables requires further investigation.

A knowledge gap highlighted by Cheung and Vogel (2013) indicates the limited number of researches on tourist behaviour towards technology acceptance models, such as mobile applications, which supports the reasoning for conducting this research. Furthermore, the studies by De Oliveira Nunes and Mayer (2014), Huang et al. (2013) as well as Kennedy-Eden and Gretzel (2012) suggest that because of the rapid change in the usage of mobile technologies by consumers and other users, tourism providers should reconsider their approach. The software developers should design and implement mobile applications for specific segments of the tourism industry, such as the tourism business event providers, tourists visiting professional exhibitions and events in South Africa.

The present article reports on a study that explored the adoption and use of technology by tourism providers in the context of business event tourism. It capitalises on extant literature and previous studies conducted by Acarli and Saglam (2015), Ayeh (2015), Davis, Bagozzi and Warshaw (1989), Huang et al. (2013), Jongchul and Sung-Joon (2014), Kim et al. (2008b), Kim, Park and Morrison (2008a) and Teo, Luan and Sing (2008). Based on the extant literature, a research project was designed and carried out with the aim of investigating the key aspects of the adoption and use of mobile applications by tourism providers and tourism trade exhibition visitors. Previous research (Davis 1989; Rodrigues \& Carvajal-Trujillo 2014) suggests the three main constructs in the TAM: (1) ease of use, (2) perceived usefulness and (3) behavioural intentions.

Therefore, the purpose of this article was to investigate the need for the development of a TAM for business event tourism as an enabling technology to adopt technology. The remainder of the article is structured as follows. In the next section (Review of literature and theoretical background), a review of the related literature and the theoretical background are discussed and a conceptual model along with the advanced hypotheses is presented. We then present the study or empirical investigation ('Research design and methods' section), encompassing the research design, methodology applied, analysis of results and study's findings. The article is completed with the conclusion and implications, and limitations and avenues of the study for future research.

\section{Review of literature and theoretical background}

The TAM is generally accepted by academic research and has been widely used in various fields and contexts as outlined below. Firstly, in the education and information technology: the study by Teo et al. (2008) investigated the intention of Singaporean and Malaysian pre-service teachers to use the TAM within a school and/or teaching environment. A similar study was conducted by Acarli and Saglam (2015) in which 
pre-service teachers' intention to use social media in teaching activities was investigated using the TAM. The study by Cheung and Vogel (2013) focused on predicting the user's acceptance of collaborative technologies. In this research, the authors investigated how the usage of technology in e-learning can be incorporated and introduced to people wanting to complete an online course.

Secondly, in the context of tourism industry, a number of studies were conducted, for example Huang et al. (2013), Ayeh (2015), De Oliveira Nunes and Mayer (2014), Herrero and Martin (2012), Kennedy-Eden and Gretzel (2012), Kim et al. (2008a, 2008b) and Xia et al. (2018). These studies adopted and applied the TAM in the field of tourism, indicating interesting findings and recommendations, which are discussed in the following paragraphs.

Ayeh (2015) investigated the acceptance of user-generated content (UGC) by tourists. This study particularly focuses on the increasing growth of social media for tourism purposes, such as information gathering and sharing, sharing of experiences, and discusses related aspects. It was found that the perceived usefulness had both a direct and indirect impact on the intention of tourists to use technological tools. Furthermore, the usefulness of UGC is influenced by the intention to use the technology by tourists for planning purposes if they have the perception that it is useful. It can therefore be argued that the perceived ease of use (PEU) is determined by the ease or friendly use of technologies.

It should be pointed out that the model developed by Ayeh (2015) has three insignificant relationships. Firstly, there is no direct relationship between perceived trustworthiness and usage intention. However, the impact of perceived trustworthiness on the attitude and usefulness has been investigated throughout the study. Secondly, the perceived expertise has neither a direct effect on perceived usefulness nor a direct effect on usage intention. Thirdly, attitude constitutes the main factor influencing the intention of using technology. Therefore, it could be argued that tourists' attitude determines the adoption, use and development of technology. The study by De Oliveira Nunes and Mayer (2014) found that the introduction of a mobile application within a nature-based tourism destination had significant impact on the tourists' experiences. The study's findings suggest that tourists who used a purpose-designed mobile application experienced it as being fun, useful, easy and compatible with the destination.

The studies by Kennedy-Eden and Gretzel (2012) and Kim et al. (2008a) suggest that the extensive usage of mobile applications plays a significant role in the development of mobile applications in the tourism industry. This suggestion is supported by Neuhofer, Buhalis and Ladkin (2012), adding that new technologies for tourism destinations had valuable contribution to tourists' experiences. Tourism destinations and providers should, therefore, adopt and use new technologies in order to improve the level of customisation of experiences and increase the resulting satisfaction.
The study by De Oliveira Nunes and Mayer (2014) indicated that the main drivers behind the extensive spread and usage of mobile applications are usefulness, compatibility and perceived enjoyment. It was found that people who are using mobile applications in their everyday life (personal and/or professional), as well as the younger generation, consider the usefulness as a very important factor. If tourists do not find mobile applications easy to use, they will not adopt and use them. The study by De Oliveira Nunes and Mayer (2014) concluded that the introduction of a destination mobile application is valuable for public tourism organisations and private businesses in two fields, namely the provision of relevant information and promotion of engagement, and interaction between tourism providers and tourists.

The use of mobile technology in the tourism industry could provide exceptional opportunities for organisations and businesses in capturing the attention of their targeted market segments and enhancing loyalty. The study by Kim et al. (2008b) developed a model that explains how tourists accept the usage of technology when travelling. The findings indicated that the majority of tourists have a positive experience when using mobile applications and need tools that are more similar. Developers of mobile applications for the tourism industry should understand that there is a demand for effective mobile applications that offer a wider variety of mobile scope and services within tourism destinations as the demand by tourists using mobile applications is increasing. Furthermore, Kim et al. (2008a) indicated that the factors PEU and perceived usefulness are key to the development of mobile applications for tourist consumers. Perceived usefulness also showed a significant relationship $(p<0.01)$ with the attitudes of tourists in using the mobile devices.

The study conducted by Xia et al. (2018) about Macau confirms that perceptions about using mobile applications are similar to that of computer-based technologies. This study confirmed the effectiveness of destination marketing organisations' (DMOs) mobile applications, which were proven the most influential antecedents of the potential tourists' cognitive beliefs. The study suggests that DMOs should find ways in which the mobile applications should be managed more effectively and efficiently in order to enhance the visitors' online experience.

The three constructs, along with the resulting research hypotheses advanced by the present study, are discussed in the following subsections.

\section{Business event tourists' perceived usefulness of online technology (BT_POU)}

Scholars such as Davis (1989), Kim et al. (2008a) and Pearson and Grandon (2004) suggest that individuals should believe that the use of mobile applications would be beneficial to their life; otherwise, they will not use them. Furthermore, it is believed that the use of mobile applications across the tourism industry could be very effective if tourists and 
employees are aware of the resulting benefits in their travelling experiences and work (Teo et al. 2008). The study by $\mathrm{Oh}$ and Yoon (2014) indicates that the confidence in the usage of a mobile application is resulting in higher probabilities of usage by consumers.

In the context of business events tourism, a mobile application could increase clientele loyalty and promote the business offerings and interaction with tourists and providers of business events tourism services. It is believed that the implementation of a mobile application in the business events tourism industry could add additional value to the event (De Oliveira Nunes \& Mayer 2014). Perceived usefulness is the belief by tourists that using the application for an event or conference would improve their event experience (De Oliveira Nunes \& Mayer 2014). A key aspect that tourism providers should consider is that the mobile application must be enticing, informative and interactive and must offer online services which are efficient and effective (Fernandez-Cavia \& Lopez 2013; Han et al. 2016).

The usage of new mobile applications would allow providers of business events tourism services (i.e. events planners and conferences organisers) to create not only memorable tourist experiences within the physical setting but also an extended or augmented experience in the virtual space (De Oliveira Nunes \& Mayer 2014). However, the crucial point for tourism providers is to design and implement properly the innovative technologies in order to achieve higher perceived usefulness compared to other technological tools, such as Skype and other messaging applications. This, in turn, could lead tourists to fully realising the benefits and advantages of using mobile technology and its perceived usefulness (Herrero \& Martin 2012; Oh \& Yoon 2014). Based on the latter, there is sufficient theoretical evidence to formulate the following hypothesis $\left(\mathrm{H}_{1}\right)$ :

$\mathbf{H}_{1}$ : Business event tourists' perceived usefulness of online technology can be reliably and validly measured.

\section{Business event tourists' perceived ease of use of online technology (BT_PEOU)}

According to Oh and Yoon (2014), there is a steady growth of people being confronted with large amounts of information and not knowing always how to handle this information. Therefore, there is a need for introducing Haptic Enabling Technology, which assists people in this task. This particular technology is also embedded into various applications to enhance the transfer of information between a virtual environment and a human environment, and vice versa (Oh \& Yoon 2014). When the developers of applications create a new mobile application purpose-designed for a specific industry, they must have a consumer-driven approach and must ensure that consumers (in this case tourists) will be able to use the application for achieving the expected benefits (De Oliveira Nunes \& Mayer 2014).

Scholars such as Ayeh (2015), Oh and Yoon (2014) and Cheung and Vogel (2013) suggest that the dimension 'PEU' has significant influence on whether a tourist believes that the usage of the mobile application would be effective or not. The study by Oh and Yoon (2014) indicates that the consumers' attitude depends on whether they would intend to adopt and/or buy the mobile technology and later on actually use it. By using a mobile application in the context of a business event, the providers of tourism services would be in a position to promote innovative products and services effectively, which may increase the business tourists' perceived usefulness of the application (Oh \& Yoon 2014). Based on the above discussion, there is sufficient theoretical evidence to formulate the following hypothesis $\left(\mathrm{H}_{2}\right)$ :

$\mathbf{H}_{2}$ : Business event tourists' PEU of online technology can be reliably and validly measured.

\section{Business event tourist's intention to use online technology (BT_OIU)}

The behaviour of tourists using a new technology or tool is based on their perceptions regarding that technology or tool, and the perception is determined by two main factors: attitude and perceived usefulness (Herrero \& Martin 2012). The study by Herrero and Martin (2012) suggests that the perceived usefulness of new technology has an influence on tourists' attitude and perceptions of ease of use. Ayeh (2015) and Kaplanidou and Vogt (2006) share the same opinion, indicating that tourists' attitudes towards new technology could have a positive effect on its adoption and usage on a trip or tour. Therefore, it could be argued that we should consider the influence of external variables related to new technological developments on the tourists' perceptions about usefulness and ease of use.

The aim of the TAM is to determine whether the consumer and/or user behaviour will switch into using the new technology based on the perceived usefulness and ease of use (Amaro \& Duarte 2015; Ayeh 2015). It was found that the provision of information to tourists is aiming at influencing their perceptions of usefulness of the new technology; this will have an impact on their attitude and intentions of using the new technology when travelling (Kim et al. 2008a). Cheung and Vogel (2013) argue that influence along with attitude is an important factor to consider in determining tourists' behavioural intention to use new technology. Huang et al. (2013) indicate that tourists' perceptions of ease of use and usefulness determine whether they would share information regarding their tourism experiences on websites (online reviews). However, Kim et al. (2008a) argue that a low quality of information and communication technology services (mainly speed) might have a significant (dissuasive) influence on the usage of a mobile application. Hence, it can be argued that in order for tourist behaviour to change into action, the technology should ensure that the ease of use and usefulness of the technology is to the benefit of the tourists, not knowing that it enhances the tourism provider as well.

Based on the above discussion, there is sufficient theoretical evidence to formulate the following hypothesis $\left(\mathrm{H}_{3}\right)$ :

$\mathbf{H}_{3}$ : Business event tourists' intention to use online technology can be reliably and validly measured. 


\section{The prediction of business event tourist's intention to accept technology}

Apparently, the technological developments result in an imperative for the tourism destinations and providers, that is, the incorporation of more technology-based products and services to enhance tourists' experience (Neuhofer et al. 2012). Various scholars, such as Natarajan, Balasubramanian and Kasilingam (2018), Tan et al. (2018), Ayeh (2015), Cheung and Vogel (2013), Herrero and Martin (2012) and Huang et al. (2013), have pointed out the importance of closely monitoring the mobile application users' perceptions about its usefulness and ease of use; this perception is the main factor influencing the intention to use the technological tool. The intention to accept mobile technology is based on the lesser efforts required by users to learn how to use the technology as the ease of use influences user's confidence levels of using the mobile technology (Tan et al. 2018). If the ease of using mobile technology conveniences users' lives, the intention to use and accept the mobile technology is higher (Natarajan et al., 2018). In the context of business tourism, the intention to use can enhance and facilitate interactive conversations and engagement in collaborative discussions between stakeholders involved (organisers and/or providers, exhibitors and professional visitors). Nevertheless, the investigation towards prediction was of use and intention to use is not the focus of this study.

$\mathbf{H}_{4}$ : The scores on the business event tourists' perceived usefulness of online technology, scores on business event tourists' PEU of online technology, can serve in a prediction model of business event tourists' intention to accept technology (BT_IAT).

This hypothesis was formulated to determine if BT_POU (independent variable) or BT_PEOU (mediating variable) would emerge as an independent predictor of BT_IAT (dependent variable), when all these variables were simultaneously entered into the equation, as illustrated in Figure 1.

Figure 1 was designed based on the guidelines and suggestions formulated by Kennedy-Eden and Gretzel (2012) for further investigations into designing mobile applications to support tourism industry in delivering more efficient and effective services. Ayeh (2015) points out that the TAM factors, perceived usefulness, ease of use and intention to use, are critical in determining tourists' intention to use consumer-generated media (CGM) to plan their trips. Herrero and Martin (2012) indicate that the ease of using

\begin{tabular}{|c|c|c|}
\hline $\begin{array}{c}\text { BT_POU } \\
\text { Independent } \\
\text { variable }\end{array}$ & $\begin{array}{c}\text { BT_PEOU } \\
\text { Independent } \\
\text { variable }\end{array}$ & $\begin{array}{l}\text { BT_OIU } \\
\text { Dependent } \\
\text { variable }\end{array}$ \\
\hline
\end{tabular}

Source: Adapted from Ayeh 2015; De Oliveira Nunes and Mayer 2014; Herrero and Martin 2012; Kennedy-Eden and Gretzel 2012; Kim et al. 2008a; and Xia et al. 2018.

Note: Please see full reference list of the article, Swart, M.P., Sotiriadis, M.D. \& Engelbrecht, W.H., 2019, 'Investigating the intentions of tourism providers and trade exhibition visitors to use technology: A technology acceptance model approach', Acta Commercii 19(1), a693. https://doi.org/10.4102/ac.v19i1.693 for more information.

FIGURE 1: Theoretical (prediction) model. websites to access accommodation information is determined by the perceived usefulness of the tourists before using the website. Kim et al. (2008a) found that during tourists' travels, the perceived usefulness of a mobile application is higher and the adoption of mobile application is facilitated only if the mobile application is easy to use. A direct relationship exists between perceived usefulness and behavioural intention, as well as PEU and perceived usefulness, between tourists travelling to virtual tourism websites as suggested by Huang et al. (2013). This aspect supports the suggestion by De Oliveira Nunes and Mayer (2014) that the younger generation is keener to use technology in their everyday life activities.

The use of technology in the tourism industry provides two benefits: (1) improvement of the competitive advantage that tourism organisations can achieve on the premise that the technology is easy to use and (2) provision of evidence of usefulness in the work place that ultimately leads to intention to use because of its functionality allowing improvement of work performance (Kim et al. 2008b). The latter is further supported by Xia et al. (2018), suggesting that if there is a high level of perceived usefulness and quality of information provided together with easy navigation of DMO websites and mobile applications, it leads to tourists using the available mobile technologies to access information.

A study was designed and carried out aiming at empirically investigating the suggested theoretical model for prediction of the intentions of tourism providers and tourism trade exhibition visitors to use technology in the context of business events tourism. The following section deals with this empirical study.

\section{Research design and methods}

The main elements of the empirical study and its findings are presented in the following subsections.

\section{Research approach and method}

This study adopted a quantitative, inductive research approach. Data were analysed through the application of general linear modelling (GLM) procedures. The research method applied is outlined below by presenting the sampling and participants, research procedure, measurement instruments and the statistical analysis performed.

\section{Sampling and participants}

The study was conducted on a population of tourism trade exhibition visitors who attended HuntEx $2015(n=403)$. The sample consisted of six groups: (1) hunters, (2) sport shooters, (3) gun collectors, (4) game farmers, (5) professional hunters and (6) anglers. Based on the empirical nature of the study, a purposive, non-probability sampling technique was selected to explain the selected target population. Tourism trade exhibition visitors were sampled based on their attendance of HuntEx from 24 to 27 April 2015. Hair et al. (2010) provide a guideline as follows: for every one item in the measurement instrument, 
a minimum of 5-10 respondents are required if multivariate data analysis techniques are used. In this study, four items per construct were included in the measurement instrument, which required a minimum of 120 responses. The 403 collected questionnaires exceeded the minimum requirement and supported the results from the multivariate data analysis.

\section{Research procedure}

Question format items in a newly developed questionnaire measured constructs. After obtaining the respondents' consent, an e-survey, using Lime Survey, was administered by trained fieldworkers to collect the primary data. All completed questionnaires $(N=403)$ were submitted online by the fieldworkers. The latter could not submit the online questionnaire if the questionnaire was not fully (100\%) completed, which improved the response rate and supported the researchers in validating all the responses.

\section{Measuring instruments}

To explore the constructs of the business events tourists' intention to accept online technology model, hypotheses were formulated and tested using a three-step process. Firstly, the theoretical model was developed to depict the relationships among perceived usefulness, PEU and online intention to use. Secondly, the model was benchmarked with similar online models. This resulted in three measuring instruments: the perceived usefulness of online technology, perceived ease of use of online technology, and intention to use online technology, which were included in the construction of the final instrument. The BT_POU Scale (Acarli \& Saglam 2015; Ayeh 2015; Herrero \& Martin 2012; Huang et al. 2013; Jongchul \& Sung-Joon 2014), the BT_PEOU Scale (Acarli \& Saglam 2015; Ayeh 2015; Herrero \& Martin 2012; Huang et al. 2013; Jongchul \& Sung-Joon 2014) and the BT_OIU Scale (Acarli \& Saglam 2015) consisted each of four items.

A seven-point intensity scale was used to measure responses on each item for all three scales. This Likert-type scale was anchored at extreme ends. Supported by the measurements test (Hair et al. 2010), all three instruments proved to be reliable and valid (Acarli \& Saglam 2015; Ayeh 2015; Herrero \& Martin 2012; Huang et al. 2013; Jongchul \& SungJoon 2014). Finally, the prediction of BT_IAT was tested by comparing path differences among the model's results for the constructs, as suggested by Hair et al. (2010). These three steps were all performed through a GLM procedure using IBM SPSS 24.0, which is a family of models consisting of variables, a random component and a link function to indicate the type of conversions needed to accommodate the different model formulations (Hair et al. 2010). The use of GLM is consistent with the investigation of technology acceptance in studies related to education (Visser 2011) and retail (Ezeh \& Olawale 2017).

\section{Statistical analysis}

An exploratory factor analysis (EFA) and a confirmatory procedure are the two factor-analytical approaches used to examine the interrelationships in the measure. The confirmatory procedure is used to investigate the unidimensionality and construct validity, and indicates how well the theoretical specifications of each construct match the data. All the items of each construct had to be inter-correlated and tested for factor analyses. An inferential analysis yielded the numerical properties of the population, which were used to inform the researcher in predictions about the population and in assigning probabilities to these predictions. The Pearson product-moment correlation coefficient $(r)$ reveals the strength and the direction of the relationships.

General linear modelling was used to determine the role of the perceived usefulness of online technology (BT_POU) in predicting the intention to use online technology (BT_OIU). Multivariate GLM has become a popular means of estimating analysis of variance (ANOVA) models, which are useful for the development of theories from newly generated predictive models, as in the case of this study. A confirmatory procedure and the examining of the structural relationships in terms of the model fit and the structural parameter estimates (Pallant 2007) validate theories. A multi-factor ANOVA was performed to ascertain if the BT_POU and the BT_PEOU variables can predict BT_OIU, either jointly or separately. This process aimed at identifying the main and interactional effects of the factors (categorical independent variables) on an interval (Hair et al. 2010) dependent variable. A regression analysis was used to undertake a correlational analysis. Preliminary analyses were conducted to ensure no violation of the assumptions of normality, homoscedasticity, linearity and multi-collinearity. Three steps were proposed for the GLM construction using IBM SPSS Version 24.0 (Hair et al. 2010).

In building the most parsimonious predictive model of business event tourists' intention to accept technology was to enter the BT_POU together with BT_PEOU stepwise into the equation in order to attain residuals through the DurbinWatson statistic. This presented an initial model of variables explaining BT_OIU. This model summary highlighted the $\Delta R^{2}$ and the coefficients with $\beta$-values. $R^{2}$ is the portion of variance in $Y$ (BT_OIU) explained by the regression equation (predictors). The main results are presented and discussed in the following section.

\section{Ethical consideration}

Ethical clearance was obtained from the University of South Africa (Unisa) College of Economic and Management Sciences (CEMS) ethics committee (Reference number: 2013 CEMS_014).

\section{Results and discussion Reliability and validity}

Based on the EFA, the three measurement instruments were proven reliable and valid. The overall significance of all correlations was supported by the Bartlett's test of sphericity (>0.6) and Kaiser-Meyer-Olkin (KMO) measure 
of sampling adequacy (MSA) (>0.3) (Hair et al. 2010), when a test was conducted on BT_POU, BT_PEOU and BT_OIU. All the three constructs were significant $(\rho \leq 0.05)$, namely (1) BT_POU $\left(\mathrm{H}_{1}\right)$ Bartlett's test of sphericity $\left(X_{(d f=6 ; \rho \leq 0.01)}^{2}=\right.$ 808.33) and KMO MSA (0.83) supported the significance of the construct $(\alpha=0.87$ ), with one factor explaining $72.71 \%$ of the variance (four items); (2) BT_PEOU $\left(\mathrm{H}_{2}\right)$ was significant $(\alpha=0.85)$ where the Bartlett's test of sphericity $\left(X_{(d f=6 ; \rho \leq 0.001)}^{2}=727.35\right)$ and KMO MSA (0.78) indicated a one factor solution explaining $69.67 \%$ of the variance (four items); lastly (3) the Bartlett's test of sphericity $\left(X_{(d f=6 ; \rho \leq 0.01)}^{2}\right.$ $=725.02)$ and KMO MSA (0.79) indicated the overall significance $(\alpha=0.84)$ of BT_OIU $\left(\mathrm{H}_{3}\right)$, where this one factor explains $69.28 \%$ of the variance. Following these results, the three hypotheses $\left(\mathrm{H}_{1}, \mathrm{H}_{2}\right.$ and $\left.\mathrm{H}_{3}\right)$ are supported and can be accepted.

A Kolmogorov-Smirnov test was conducted to statistically determine the normality of the distribution on all the three constructs (Pallant 2007). BT_POU, BT_PEOU and BT_OIU were significant $(\rho \leq 0.05)$, but the Kolmogorov-Smirnov test is sensitive to larger samples $(n=403)$. As sample size was relatively big (>200), the test normality is not critical and is regarded as an underestimation of the variance (Tabachnick \& Fidell 2007). Following these results the relationships between the constructs must be significant to allow for the testing of the final parsimonious model. Therefore, the Pearson product-moment correlation was conducted to determine the inter-correlation of the constructs. The scores between BT_POU and BT_PEOU were statistically significantly positively related. The Pearson productmoment correlation coefficient was $r=0.63, n=403(\rho \leq 0.01)$, with a large effect size. The BT_PEOU and BT_OIU scores were $r=0.57, n=403$ ( $\rho \leq 0.01)$, indicating a statistically significant positive relationship, with a medium effect size. The significance of the data was supported as $r=0.57, n=403$ $(\rho \leq 0.01)$ were statistically significantly positively related, indicating that scores between BT_PEOU and BT_OIU had a medium effect size. As all the relationships between the constructs were significant, the possibility of a business event tourists' intention to accept technology model can be explored.
In building the most parsimonious predictive model of BT_ OIU (dependent variable) was to enter the two independent variables, BT_POU and BT_PEOU, stepwise into the equation, in an attempt to achieve residuals through the DurbinWatson statistic. Table 1 outlines a summary model of BT_ POU and BT_PEOU when entered into the equation, as well as the coefficients of the variance, explaining the variance in BT_OIU.

Based on the results shown in Table 2, the BT_POU explained the most variance in BT_OIU at 32\%. If BT_PEOU was included in the model, an additional 7.5\% $(39.3 \%$ $31.8 \%$ ) was added than what BT_POU already explained. The interaction between BT_POU $\times$ BT_PEOU explained the same variance in BT_OIU at 39.3\%, as what the BT_POU and BT_PEOU already explained, as BT_POU $\times$ BT_PEOU is the average difference between BT_POU and BT_PEOU. However, when BT_POU and BT_PEOU together with BT_POU $\times$ BT_PEOU are entered as independent variables of the model, BT_POU is omitted and BT_PEOU is insignificant $(\rho=0.52)$. There is no statistical difference between BT_POU and BT_PEOU when entered into an equation with BT_POU $\times$ BT_PEOU. As BT_POU and BT_ PEOU were omitted from the model with BT_POU $\times \mathrm{BT}_{-}$ PEOU, the model remains the same as additional degrees of freedom are added to BT_POU $\times$ BT_PEOU to ensure that the overall degrees of freedom and model fit do not change.

Thus, $39.4 \%$ of the variance in BT_OIU was explained by entering BT_POU $\times$ BT_PEOU (independent variables) into the equation. The Durbin-Watson statistic had a value of 1.96 , which was within the required range of 1.00-2.00. The $\rho$-value was significant $(\rho \leq 0.01)$ for most of the variables in the three models. The GLM equation for the business event tourists' intention to accept technology model was as follows:

Business event tourists' intention to accept technology = $2.02+0.62$ (BT_POU $\times$ BT_PEOU)

Data from the above discussions support the hypothesis, stating that scores on the BT_POU and BT_PEOU scales

TABLE 1: A summary general linear modelling for predicting business event tourist's intention to use online technology $\uparrow$ (initial model to obtain residuals).

\begin{tabular}{|c|c|c|c|c|c|c|c|c|c|}
\hline \multirow[t]{2}{*}{ Model } & \multirow[t]{2}{*}{$R$} & \multirow[t]{2}{*}{$R^{2}$} & \multicolumn{3}{|c|}{ UnStd Coeff } & \multirow{2}{*}{$\begin{array}{c}\text { Std Coeff } \\
\beta\end{array}$} & \multirow[t]{2}{*}{$t$} & \multirow[t]{2}{*}{$\rho$} & \multirow[t]{2}{*}{ Durbin-Watson } \\
\hline & & & $\Delta R^{2}$ & $B$ & $S E B$ & & & & \\
\hline Predictors: (Constant) & - & - & - & 3.09 & 0.190 & - & 16.11 & $\leq 0.01$ & \\
\hline BT_POU & $0.57 \ddagger$ & 0.32 & 0.32 & 0.51 & 0.040 & 0.57 & 13.73 & $\leq 0.01$ & 1.95 \\
\hline Predictors: (Constant) & - & - & - & 2.02 & 0.240 & - & 8.59 & $\leq 0.01$ & \\
\hline BT_POU§ & $0.63 \S$ & 0.40 & 0.39 & 0.31 & 0.045 & 0.34 & 6.82 & $\leq 0.01$ & \\
\hline BT_PEOU $\S$ & & & & 0.37 & 0.052 & 0.36 & 7.08 & $\leq 0.01$ & 1.96 \\
\hline Predictors: (Constant) & - & - & - & 2.02 & 0.230 & - & 8.59 & $\leq 0.01$ & \\
\hline BT_PEOUף & 0.639 & 0.34 & 0.39 & 0.06 & 0.090 & 0.05 & 0.64 & 0.52 & \\
\hline BT_POU $\times$ BT_PEOU & & & & 0.62 & 0.090 & 0.58 & 6.82 & $\leq 0.01$ & 1.96 \\
\hline
\end{tabular}

$R$, correlation coefficient; $R^{2}$, coefficient of determination; $\Delta R^{2}$, adjusted coefficient of determination; $B$, unstandardised coefficient and constant for linear regression equation; $\beta$, the standard regression coefficient; SEB, standard error of $B$; $\rho$, probability value, Std, standardised; UnStd, unstandardised, coeff, coefficient; BT_POU, business event tourists' perceived usefulness of technology; GLM, general linear modelling; BT_PEOU, business event tourists' perceived ease of use of online technology; BT_OIU, business event tourist's intention to use online technology.

$\dagger$, dependent variable: BT_OIU.

\$, predictors: (Constant), BT_POU.

$\S$, predictors: (Constant), BT_POU, BT_PEOU.

I, predictors: (Constant), BT_PEOU, BT_POU $\times$ BT_PEOU. 
TABLE 2: Factor matrix for business event tourists' perceived usefulness of technology, business event tourists' perceived ease of use of online technology and business event tourist's intention to use online technology.

\begin{tabular}{|c|c|c|c|c|}
\hline Items & BT_POU $\dagger$ & BT_PEOU & BT_OIU§ & Reliability \\
\hline B8_How effective are mobile applications during the purchasing process & 0.87 & - & - & 0.87 \\
\hline B7_In your opinion, is it quicker to use mobile applications to purchase products & 0.81 & - & - & \\
\hline B6_How useful are mobile applications when making purchases & 0.77 & - & - & \\
\hline B9_Do mobile applications assist you in planning your online purchases & 0.74 & - & - & \\
\hline B12_How easy is it for you to learn how mobile applications work & - & 0.85 & - & 0.85 \\
\hline B13_How skilful do you consider yourself in the use of mobile applications & - & 0.81 & - & \\
\hline B11_How easy is it for you to interact with other people through mobile applications & - & 0.72 & - & \\
\hline B10_How convenient is it for you to use mobile applications & - & 0.71 & - & \\
\hline B15_Will you use the mobile application & - & - & 0.92 & 0.84 \\
\hline B17_Will you use the application to plan your visit to HuntEx & - & - & 0.78 & \\
\hline B14_Do you agree that the use of a mobile application will enhance your experience of HuntEx in future & - & - & 0.70 & \\
\hline B16_Will you use the mobile application to make purchases & - & - & 0.68 & \\
\hline
\end{tabular}

Note: Extraction method: principal axis factoring; rotation method: Varimax with Kaiser normalisation.

BT_POU, business event tourists' perceived usefulness of technology; BT_PEOU, business event tourists' perceived ease of use of online technology; BT_OIU, business event tourist's intention to use online technology.

$\dagger$, one factor extracted, seven iterations required.

$\$$, one factor extracted, seven iterations required.

$\S$, one factor extracted, 10 iterations required.

(with BT_POU $\times$ BT_PEOU) can serve in the prediction model of business event tourist's intention to accept technology. The data therefore support $H_{4}$.

\section{Findings and discussion}

This study has developed and suggested a modified TAM model suitable to the business events tourism industry. This arises from the challenge faced by providers of tourism services in understanding the relevance and impact of technology in consumer behaviour and decision-making processes. The design and development of mobile applications are expensive. That is the reason why it is necessary to establish if there is a need for such a technological tool among business event tourists when they visit an exhibition or other similar events.

The latter is supported by studies carried out by De Oliveira Nunes and Mayer (2014), Neuhofer et al. (2012) and Kaushik et al. (2015), indicating that purposeful mobile technology is designed with two aims: convenience and added value to business event tourists' experience. Three constructs were proposed for the development of a business event tourists' intention to accept technology model, namely BT_POU, BT_ PEOU and BT_OIU. De Oliveira Nunes and Meyer (2014) emphasised the usefulness of a mobile application in the tourism industry, while Kim et al. (2008a) supported this notion as the usefulness of the technology can stimulate loyalty among tourists. BT_POU supported the findings of De Oliveira Nunes and Meyer (2014) and Kim et al. (2008a) as the four items selected in the measurement of construct were supported by the data $\left(\mathrm{H}_{2}\right)$ with a significance of $\alpha=0.87$.

Kim et al. (2008a) highlighted the necessity to include technology usefulness in the investigation of technology acceptance among tourists. BT_PEOU was developed and consisted of four items, which has a significant measurement ( $\alpha=0.85$ ) for the construct supporting $\mathrm{H}_{2}$. The results of this study are consistent with the findings of Kim et al. (2008a, 2008b), making a contribution to the body of knowledge that the ease of technology use is important to the overall acceptance of a technology tool in the business tourism context. Davis (1989) investigated the intention to accept technology as part of the TAM. This was later supported by research in the tourism field, such as Rodrigues and CarvajalTrujillo (2014), among passengers travelling with a low-cost airline. BT_OIU was developed and had a significance of $\alpha=0.84\left(\mathrm{H}_{3}\right)$, supporting all four items included in the construct. BT_OIU, as a newly developed construct, addresses the gaps in the current literature as it highlights the necessity to consider the intention of business tourists to use a technology tool.

The relationships between the three new constructs were examined in support of the development of the final business event tourists' intention to accept technology model. A Pearson product-moment correlation coefficient was calculated for all the three relationships. The relationships between BT_POU and BT_PEOU, BT_POU and BT_OIU, and BT_PEOU and BT_OIU $(\rho \leq 0.01)$ were statistically significantly positively related, making a contribution by supporting the inclusion of usefulness, ease of use and intention to use the mobile application in a business events tourism context.

Finally, the most parsimonious model of business event tourists' intention to accept technology was investigated using GLM, where $39.4 \%$ of the variance in BT_OIU was explained by entering BT_POU $\times$ BT_PEOU (independent variables) into the equation with a Durbin-Watson statistic value of $1.96(\rho \leq 0.01)$. The GLM equation for the business event tourists' intention to accept technology model was calculated as $2.02+0.62$ (BT_POU $\times$ BT_PEOU), which supported $\mathrm{H}_{4}$.

The results of this study provide evidence about the perceptions and the interrelationships between the determining factors. The usefulness, ease of use and the intention to use technology among business event tourists are positive and effective factors, and all add value to the 
overall experience, confirming the suggestions of previous studies investigating the same topic in other contexts and settings (Ayeh 2015; De Oliveira Nunes \& Mayer 2014; Kim et al. 2008b; Neuhofer et al. 2012).

\section{Conclusion and implications}

Tourism providers and destinations are facing new types of issues and challenges in the digital era and information and communication-dominated markets. The use of mobile technology has become one of the most essential tools for business tourists to communicate with (Dinh et al. 2011). The purpose of this study was to investigate the key aspects of the adoption and use of mobile application in its simplest form (Mortenson \& Vidgen 2016) by business event tourists. The reasoning driving our choice for the TAM model in determining the level of acceptance of technology by business event tourists in the events industry was based on the prominence of the TAM theory and its adoption and empirical investigation in the various tourism-related contexts and settings.

This study firstly suggested a conceptual (prediction) model based on four hypotheses of interrelationships. Against this background, a prediction model of business event tourists' intention to accept technology has been developed as informed by the TAM approach. This model was empirically investigated in the context of business event tourism, a professional exhibition. The results support the development of a predictive model of business event tourists' intention to accept technology consisting of BT_POU, BT_PEOU and BT_ OIU. This final multivariate and empirical business event tourists' intention to accept technology model confirms that the purpose of the study has been achieved. This addresses a recommendation made by Xia et al. (2018) that further investigations should be carried out on the opportunities available for researchers to expand the TAM model on the perceived usefulness of mobile applications within the business event tourism industry.

This study contributes to our knowledge from a theoretical, methodological and practical perspective. Firstly, the suggested conceptual model for prediction incorporates three newly developed constructs, BT_PEOU, BT_POU and BT_OIU, and provides guidance on how business event tourists (tourism providers and tourism trade exhibition visitors) intend to accept technology. This study supports the inclusion of the usefulness of technology when the acceptance of technology is studied in a business event tourism context, contributing to the current literature field.

Our research extends existing theory by incorporating new elements and empirically investigating them within a new context. The innovative element of this approach is the integrated consideration, the simultaneous examination of these constructs and the investigation of their interrelationships. Secondly, a significant methodological contribution was made through the testing of the intention of business event tourists to accept technology through GLM, revealing and identifying critical aspects of their intentions.

Thirdly, it is believed that the study's findings are valuable to industry practitioners. In the development of mobile technology for the business event tourism industry, the three constructs are valuable guidelines about the factors determining the acceptance and adoption of the specific technology. These factors - usefulness, ease of use and the intention to adopt and use technology - have to be taken seriously into account in the marketing management plans aiming at influencing the tourists' decision-making process. In the formulation of business and marketing strategies, the usefulness, ease of use and intention to use online technology can inform decisions and the justification of the cost associated with the development of technological tools and applications.

These findings are of practical importance to managers, marketers and owners of enterprises of business event tourism, such as exhibitions and conference organisers and events planners, in the sense that they indicate the adequate approach they have to adopt - consumer/user centric - and the strategies - interactive communication and friendly use to influence the acceptance and use of these technological tools. The same stands for the software developers of mobile applications and similar communication tools; when they design these tools, they must bear in mind the factors determining the adoption and the purposes of use by the targeted consumer market segment.

Ultimately, the positive relationships between the factors investigated by this study demonstrate that information and communication technology has significant potential and provides opportunities for the tourism providers to enhance the online experience and to add value to the whole experience of business events and leisure tourists.

\section{Limitations and avenues for future research}

This study contributed to our knowledge of the technology acceptance in the field of tourism; however, it entails some limitations. Firstly, as for the research design, this study was limited to one tourism business event (a professional exhibition) in South Africa and interviews were conducted during a specific time period. The testing and development of the business event tourists' intention to accept technology model was limited to one exhibition held in Gauteng province, and may be reinforced by involving more business tourist events held at local and international destinations.

Secondly, non-probability sampling techniques were used. These techniques may make the BT_POU, BT_PEOU and BT_OIU results vulnerable. As technology tools enable data analytics, future studies may consider stratified or cluster sampling, once the mobile application has been developed and its actual use is investigated. Structural equation modelling is a popular data analytic method in the investigation of TAM (Al-Gahtani 2016; Chin \& Lin 2015; 
Ibrahim 2014; Park \& Kim 2014; Wallace \& Sheetz 2014) and can be used in the statistical analyses of future business tourism events-related studies. Ayeh (2015) and Kim et al. (2008a, 2008b) highlight the importance of user attitude in technology acceptance. The offering of personalised user experiences through the mobile application and its interactive function with the user may also add value to similar future investigations. These dimensions were not investigated in this study and are likely to influence the acceptance of technology among business event tourists. It is further suggested that business event tourists' behaviour is closely monitored in similar studies by incorporating embedded theories such as the behavioural intention theory (Fishbein \& Ajzen 1975) and the theory of planned behaviour (Ajzen 1991). These suggestions constitute interesting avenues for future research and empirical investigations.

\section{Acknowledgements}

The authors would like to thank Mr Adriaan Woudstra, organiser and managing director of Edushow CC, for the opportunity to conduct research on relevant tourism themes at HuntEx.

\section{Competing interests}

The authors declare that they have no financial or personal relationships which may have inappropriately influenced them in writing this article. The opinions expressed in this article are the views of the researchers and not an official position of the institution or funder.

\section{Authors' contributions}

M.P.S. was the main researcher of the project, supported by W.H.E. who assisted with the questionnaire design, data collection and the writing of the literature review. M.D.S. contributed to the sections 'Analysis of results and discussion' and 'Conclusion and implications'.

\section{Funding}

The organiser and managing director of Edushow CC supported in the funding of the data collection.

\section{References}

Acarli, D.S. \& Saglam, Y., 2015, 'Investigation of pre-service teachers' intentions to use of social media in teaching activities within the framework of technology acceptance model', Procedia - Social and Behavioural Sciences 176(1), 709-713. https://doi.org/10.1016/j.sbspro.2015.01.530

Ajzen, I., 1991, 'The theory of planned behaviour', Organizational Behavior and Human Decision Processes 50(2), 179-211 https://doi.org/10.1016/0749-5978 (91)90020-T

Al-Gahtani, S.S., 2016, 'Empirical investigation of e-learning acceptance and assimilation: A structural equation model', Applied Computing and Informatics 12(1), 27-50. https://doi.org/10.1016/j.aci.2014.09.001

Amaro, S. \& Duarte, P., 2015, 'An integrative model of consumers' intentions to purchase travel online', Tourism Management 46(1), 64-79. https://doi. org/10.1016/j.tourman.2014.06.006

Ayeh, J.K., 2015, 'Travellers' acceptance of consumer-generated media: An integrated model of technology acceptance and source credibility theories', Computers in Human Behaviour 48(1), 173-180. https://doi.org/10.1016/j. chb.2014.12.049
Chin, J. \& Lin, S., 2015, 'Investigating users' perspectives in building energy management systems with an extension of technology acceptance model: A case study in Indonesian manufacturing companies', Procedia Computer Sciences 72(1), 31-39. https://doi.org/10.1016/j.procs.2015.12.102

Cheung, R. \& Vogel, D., 2013, 'Predicting user acceptance of collaborative technologies: An extension of the technology acceptance model for e-learning', Computers \& Education 63(1), 160-175. https://doi.org/10.1016/j. compedu.2012.12.003

Davis, F.D., 1989, 'Perceived usefulness, perceived ease of use, and user acceptance of information technology', MIS Quarterly 13(3), 318-339. https://doi.org/10.2307/ 249008

Davis, F.D., Bagozzi, R.P. \& Warshaw, P.R., 1989, 'User acceptance of computer technology: A comparison of two theoretical models', Management Science 35(8), 982-1003. https://doi.org/10.1287/mnsc.35.8.982

De Oliveira Nunes, M. \& Mayer, V.F., 2014, 'Mobile technology, games and nature areas: The tourist perspective', Tourism \& Management 10(1), 53-58.

Dinh, H.T., Lee, C., Niyato, D. \& Wanf, P., 2011, 'A survey of mobile cloud computing: Architecture, applications and approaches', Wireless Communications and Mobile Computing 13, 1587-1611. https://doi.org/10.1002/wcm.1203

Ezeh, L.N. \& Olawale, K., 2017, 'Service quality and computer self-efficacy as predictors of consumers satisfaction of electronic banking among workers of Nnamdi Azikiwe University, Awka, Anambra State, Nigeria', International Journal of Advanced Multidisciplinary Research Reports 2(1), 1-15.

Fernandez-Cavia, J. \& Lopez, M., 2013, 'Communication, destination brands and mobile application', Communication \& Society 26(2), 95-113.

Fishbein, M. \& Ajzen, I., 1975, Belief, attitude, intention and behaviour: An introduction to theory and research, Addison-Wesley, Boston, MA.

Gavalas, D., Kenteris, M., Konstantopoulos, C. \& Pantziou, G., 2012, 'Web application for recommending personalised mobile tourist routes', The Institute of Engineering and Technology 6(4), 313-322. https://doi.org/10.1049/iet-sen. 2011.0156

Hair, J.F., Black, W.C., Babin, B.J. \& Anderson, R.E., 2010, Multivariate data analysis: A global perspective, 7 th edn., Pearson, New York.

Han, H., Park, A., Chung, N. \& Lee, K.J., 2016, 'A near field communication adoption and its impact on Expo visitors' behaviour', International Journa of Information Management 36(6), 1328-1339. https://doi.org/10.1016/j. ijinfomgt.2016.04.003

Ham, S., Kim, W.G. \& Forsythe, H.W., 2008, 'Determinants of restaurant employees' technology use intention: Validating technology acceptance model with externa factors via Structural Equation Model', in P. O'Connor, W. Höpken, U. Grezte (eds.) Information and communication technologies in tourism, pp. 441-452, Springer, Vienna.

Hew, J., Leong, L., Tan, G.W., Lee, V. \& Ooi, K., 2018, 'Mobile social tourism shopping A dual-stage analysis of a multi-mediation model', Tourism Management 66(1), 121-139. https://doi.org/10.1016/j.tourman.2017.10.005

Herrero, A. \& Martin, H.S., 2012, 'Developing and testing a global model to explain the adoption of websites by users in rural tourism accommodations', International Journal of Hospitality Management 31(1), 1178-1186. https://doi.org/10.1016/j. ijhm.2012.02.005

Huang, Y., Backman, S.J., Backman, K.F. \& Moore, D., 2013, 'Exploring user acceptance of 3D virtual worlds in travel and tourism marketing', Tourism Management 36(1), 490-501. https://doi.org/10.1016/j.tourman.2012.09.009

Huh, H.J., Kim, T. \& Law, R., 2009, 'A comparison of competing theoretical models for understanding acceptance behavior of information systems in upscale hotels', International Journal of Hospitality Management 28(1), 121-134. https://doi. org/10.1016/j.ijhm.2008.06.004

Ibrahim, H., 2014, 'Technology acceptance model: Extension to sport consumption', Procedia Engineering 69(1), 1534-1540. https://doi.org/10.1016/j.proeng.2014. 03.152

Jongchul, O. \& Sung-Joon, Y., 2014, 'Validation of Haptic Enabling Technology Acceptance Model (HE-TAM): Integration of IDT and TAM', Telematics and Informatics 31(1), 585-596.

Kaushik, A.K., Agrawal, A.K. \& Rahman, Z., 2015, 'Tourist behaviour towards selfservice hotel technology adoption: Trust and subjective norm as key antecedents', Tourism Management Perspectives 16(1), 278-289. https://doi.org/10.1016/j. tmp.2015.09.002

Kaplanidou, K. \& Vogt, C., 2006, 'A structural analysis of destination travel intentions as a function of web-site features', Journal of Travel Research 45(1), 204-216.

Kim, D., Park, J. \& Morrison, A.M., 2008a, 'A model of traveller acceptance of mobile technology', International Journal of Tourism Research 10(1), 393-407. https:// doi.org/10.1002/jtr.669

Kim, T.G. Lee, J.H. \& Law, R., 2008b, 'An empirical examination of the acceptance behaviour of hotel front office systems: An extended technology acceptance model', Tourism Management 29(1), 500-513. https://doi.org/10.1016/j.tourman. 2007.05.016

Kennedy-Eden, H. \& Grezel, U., 2012, 'A taxonomy of mobile applications in tourism', E-Review of Tourism Research 10(2), 47-50.

Lam, T., Cho, V. \& Qu, H., 2007, 'A study of hotel employee behavioral intentions towards adoption of information technology', International Journal of Hospitality Management 26(1), 49-65. https://doi.org/10.1016/j.ijhm.2005.09.002

Lee, H.Y., Kim, W.G. \& Lee, Y.K., 2006, 'Testing the determinants of computerized reservation system users' intention to use via a structural equation model', Journal of Hospitality \& Tourism Research 30(2), 246-266. https://doi. org/10.1177/1096348005285087 
Morrison, A.M., 2019, Marketing and managing tourism destinations, 2nd edn., Routledge, New York.

Mortenson, M.J. \& Vidgen, R., 2016, 'A computational literature review of the technology acceptance model', International Journal of Information Management 36(1), 1248-1259. https://doi.org/10.1016/j.jijinfomgt.2016.07.007

Morosan, C., 2010, 'Theoretical and empirical considerations of guests' perceptions of biometric systems in hotels: Extending the technology acceptance model', Journal of Hospitality \& Tourism Research 36(1), 52-84. https://doi. org/10.1177/1096348010380601

Natarajan, T., Balasubramanian, S.A. \& Kasilingam, D.L., 2018, 'The moderating role of device type and age of users on the intention to use mobile shoppin applications', Technology in Society 53(1), 79-90. https://doi.org/10.1016/j. techsoc.2018.01.003

Neuhofer, B., Buhalis, D. \& Ladkin, A., 2012, 'Conceptualising technology enhanced destination experiences', Journal of Destination Marketing \& Management 1(1), 36-46. https://doi.org/10.1016/j.jdmm.2012.08.001

Oh, J. \& Yoon, S.J., 2014, 'Validation of Haptic Enabling Technology Acceptance Mode (HE-TAM): Integration of IDT and TAM', Telematics and Informatics 31(1), 585-596. https://doi.org/10.1016/j.tele.2014.01.002

Park, E. \& Kim, K.J., 2014, 'An integrated adoption model of mobile cloud services: Exploration of key determinants and extension of technology acceptance model', Telematics and Informatics 31(1), 376-385. https://doi.org/10.1016/j. tele.2013.11.008

Pallant, J., 2007, SPSS survival manual: A step by step guide to data analysis using SPSS for Windows, 3rd edn, McGraw-Hill Open University Press, Berkshire.

Pearson, M.J. \& Grandon, E.E., 2004, 'Electronic commerce adoption: An empirical study of small and medium sized US businesses', Journal of Information and Management 42(1), 197-216. https://doi.org/10.1016/j.im.2003.12.010

Rodrigues, T.E. \& Carvajal-Trujillo, E., 2014, 'Online purchasing tickets for low cost carriers: An application of the unified theory of acceptance and use of technology (UTAUT) model', Tourism Management 43(1), 70-88. https://doi.org/10.1016/j. tourman.2014.01.017

Sigala, M., Gretzel, U. \& Christou, E., 2012, Social media in travel, tourism and hospitality, Ashgate, Surrey, UK.

Swart, M.P. \& Engelbrecht, W.H., 2017, 'Expo market segmentation variables as moderators for expo technology acceptance', African Journal for Physical Activity and Health Sciences 23(1), 170-183.
Swart, M.P. \& Roodt, G., 2009, 'A proposed model for predicting business tourist retention', Conference proceedings of the XXVI Pan Pacific Conference held in Shenzhen, China. Conducted by the Pan Pacific Business Association (PPBA), China. (ISBN: 1-931649-25-1).

Tabachnick, B.G. \& Fidell, L.S., 2007, Using multivariate statistics, 5th edn., Pearson Education, Boston, MA

Tan, G.W., Lee, V.H., Hew, J., Ooi, K. \& Wong, L., 2018, 'The interactive mobile socia media advertising: An imminent approach to advertise tourism products and services?', Telematics and Informatics 35(1), 2270-2288. https://doi.org/10.1016/ j.tele.2018.09.005

Teo, T., Luan, W.S. \& Sing, C.C., 2008, 'Cross-cultural examination of the intention to use technology between Singaporean and Malaysian pre-service teachers: An application of the Technology Acceptance Model (TAM)', Educational Technology \& Society 11(4), 265-280.

United Nations World Tourism Organisation (UNWTO), 2018, Official celebration of World Tourism Day 2018 - Tourism and the digital transformation, viewed 11 June 2018, from http://media.unwto.org/event/official-celebration-world-tourismday-2018-tourism-and-digital-transformation.

Wallace, L.G. \& Sheetz, S.D., 2014, 'The adoption of software measures: A technology acceptance model (TAM) perspective', Information \& Management 51(1) 249-259. https://doi.org/10.1016/j.im.2013.12.003

Wang, D., Park, S., Zach, F. \& Fesenmaier, D.R., 2016, 'The changing impact of the Internet on travel planning behavior', Travel and Tourism Research Association 20th TTRA International Conference 'Advancing Tourism Research Globally', viewed 8 November 2018, from https://scholarworks.umass.edu/ttra/2010/ Oral/20.

World Travel \& Tourism Council (WTTC), 2017, Travel and tourism economic impact world 2017, March 2017, viewed 22 May 2018, from www.wttc. orghttps://www.wttc.org/-/media/files/reports/economic-impact...2017/ world2017.pdf.

Visser, M.M., 2011, Towards developing an evaluation tool for business management information systems' success at public further education and training (FET) colleges in South Africa, viewed 10 June 2018, from http://uir.unisa.ac.za/ bitstream/handle/10500/5789/thesis_visser_m.pdf?...1.

Xia, M., Zhang, Y. \& Zhang, C., 2018, 'A TAM-based approach to explore the effect of online experience on destination image: A smartphone user's perspective', Journal of Destination Marketing \& Management 8(1), 259-270. https://doi. org/10.1016/j.jdmm.2017.05.002 